\title{
A mysterious upper eyelid mass in a child
}

\author{
Teena Mariet Mendonca (D) ,' Kausalya Kumari Sahu, ${ }^{1}$ Shobha G Pai, ${ }^{1}$ \\ Tishya Vepakomma ${ }^{1}$
}

${ }^{1}$ Department of Ophthalmology, Kasturba Medical College of Mangalore, Manipal Academy of Higher Education, Mangalore, India

${ }^{2}$ Department of Pathology, Kasturba Medical College of Mangalore, Manipal Academy of Higher Education, Mangalore, India

Correspondence to Dr Teena Mariet Mendonca; tmendonca87@gmail.com

Accepted 11 February 2020

\section{DESCRIPTION}

A 7-year-old girl presented with a history of gradually progressive painless mass over the right upper lid for 2 years. Her birth and developmental history was normal. There was no history of trauma to the face. No similar swellings were noted elsewhere on the body. She had no other systemic ailments. On ophthalmological examination, her visual acuity was $20 / 20$ both eyes. A pedunculated, globular, non-pulsatile upper eyelid mass (figure 1) with minimal crusting on the surface was noted, measuring around $3 \times 3 \mathrm{~cm}$. Few dilated vessels were seen on the surface of the mass. On palpation, the mass was soft, non-fluctuant and non-tender. No bruit or thrill was observed. Surface of the mass was covered by healthy eyelid skin, and base of the mass was pedunculated. There was no change in the size of the mass on Valsalva manoeuvre. Upper lid margin and tarsal conjunctival surface appeared normal. Mechanical ptosis of $3 \mathrm{~mm}$ was present on the right side. The anterior segment and fundus examination of both eyes was otherwise unremarkable, with an intraocular pressure of $16 \mathrm{~mm} \mathrm{Hg}$. CT of the orbit revealed a homogenous, isodense mass, entirely located in the preseptal area of the right upper eyelid, with well-delineated margins, but no distinguishing features contributing to the probable diagnosis. No orbital or postseptal involvement was noted on CT. The mass was excised completely through a superior eye lid crease incision. Intraoperatively, severe bleeding was encountered, which was not anticipated. Histopathological examination revealed proliferation of capillaries and thickwalled congested blood vessels with extravascular

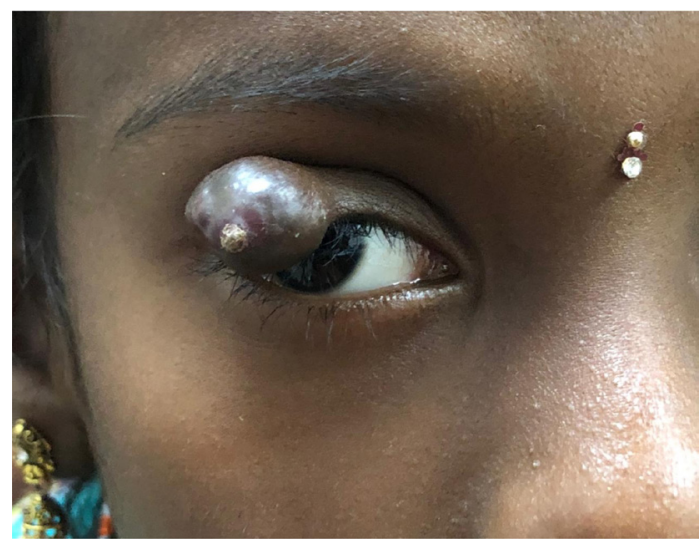

Figure 1 Clinical photograph of the patient showing pedunculated, globular, soft, non-tender, non-pulsatile, upper lid mass in the right eye. Skin over the mass was stretched and shiny with minimal crusting on the surface. Upper lid margin and tarsal surface appeared normal.

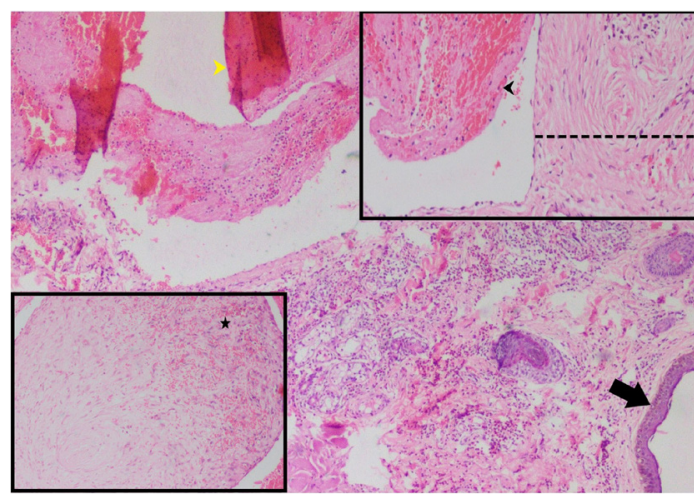

Figure $210 \times$ H\&E showing keratinised stratified squamous epithelium (black arrow) and subepithelium showing proliferation of capillaries and extravascular haemorrhagic areas (the yellow arrowhead). 40× H\&E (inset) describes congested capillaries (the star symbol), with intravascular haemorrhagic areas (the black arrowhead). The interrupted line shows the thickened vessel wall.

haemorrhagic areas, suggestive of an arteriovenous malformation (AVM). (figure 2).

AVMs in orbit are high flow conduits between arteries and veins, circumventing the intervening capillary beds, resulting in the characteristic presentation: proptosis, pain, hyperaemia, dilated corkscrew vessels, palpable thrill or bruit, and commonly associated with raised intraocular pressure. ${ }^{1}$ Orbital AVMs are extremely rare, seen in about $0.14 \%-0.5 \%$ of the population. ${ }^{2}$ AVMs are congenital hamartomas, which appear as a result of erroneous vascular maturation during 4-6 weeks of embryonic development, but may not necessarily be present at birth. The timing of their appearance depends on the type of vessel involved. ${ }^{3}$ Precipitating factors for the subsequent enlargement may be trauma, menarche or even pregnancy. ${ }^{4}$ They may grow proportionately with the patient but do not involute thereafter. ${ }^{3}$ Clinicians as well as pathologists may find it difficult to distinguish between AVMs and capillary hemangiomas. Differentiating AVMs from hemangiomas has diagnostic and prognostic ramifications. Classically, hemangiomas appear within a few weeks after birth. They obtain maximum growth during the first year of life, and typically involute within the first decade, ${ }^{6}$ whereas AVMs are complex communications between mature arteries and veins. Although AVMs are present at birth, their growth can manifest anytime later in life. The growth of AVMs is progressive and they do not involute unlike capillary heSmangiomas. However, orbital AVMs are a rare entity, and 
their presentation can be varied. Histopathologically, presence of thick-walled vessel wall is suggestive of $\mathrm{AVM}^{6}$ (figure 2).

Here, we have described a rare case of a preseptal AVM in a young child, which presented as an pedunculated, globular upper eyelid mass, with none of the diagnostic features of a typical AVM. The vascular nature of the lesion is a risk factor for uncontrolled intraoperative bleeding. It becomes crucial, therefore, to evaluate the patient thoroughly, and to adopt a multidisciplinary approach in the management of the case.

\section{Learning points}

- Arteriovenous malformations (AVMs) are one of the rare vascular abnormalities, which affect the eyelid.

- Clinical presentation of AVM may be varied, leading to a diagnostic dilemma.

- Severe, uncontrolled intraoperative bleeding should be anticipated during surgical excision of vascular lesions.

Contributors TMM: patient care and manuscript preparation. KKS: histopathology reporting. SGP: manuscript editing. TV: manuscript preparation.
Funding The authors have not declared a specific grant for this research from any funding agency in the public, commercial or not-for-profit sectors.

Competing interests None declared.

Patient consent for publication Parental/guardian consent obtained.

Provenance and peer review Not commissioned; externally peer reviewed.

ORCID iD

Teena Mariet Mendonca http://orcid.org/0000-0002-7297-386X

\section{REFERENCES}

1 Rootman J. Vascular malformations of the orbit: hemodynamic concepts. Orbit 2003;22:103-20.

2 Szajner M, Roman T, Markowicz J, et al. Onyx ( $($ ) in endovascular treatment of cerebral arteriovenous malformations - a review. Pol J Radiol 2013;78:35-41.

3 Werner JA, Dünne AA, Folz BJ, et al. Current concepts in the classification, diagnosis and treatment of hemangiomas and vascular malformations of the head and neck. Eur Arch Otorhinolaryngol 2001;258:141-9.

$4 \mathrm{Kim}$ AW, Kosmorsky GS. Arteriovenous communication in the orbit. J Neuroophthalmol 2000:20:17-19.

5 Hayes BH, Shore JW, Westfall CT, et al. Management of orbital and periorbital arteriovenous malformations. Ophthalmic Surg 1995;26:145-52.

6 Adegboyega PA, Qiu S. Hemangioma versus vascular malformation: presence of nerve bundle is a diagnostic clue for vascular malformation. Arch Pathol Lab Med 2005:129:772-5.

Copyright 2020 BMJ Publishing Group. All rights reserved. For permission to reuse any of this content visit

https://www.bmj.com/company/products-services/rights-and-licensing/permissions/

BMJ Case Report Fellows may re-use this article for personal use and teaching without any further permission.

Become a Fellow of BMJ Case Reports today and you can:

- Submit as many cases as you like

- Enjoy fast sympathetic peer review and rapid publication of accepted articles

- Access all the published articles

Re-use any of the published material for personal use and teaching without further permission

Customer Service

If you have any further queries about your subscription, please contact our customer services team on +44 (0) 2071111105 or via email at support@bmj.com.

Visit casereports.bmj.com for more articles like this and to become a Fellow 